\title{
Multiple serotonergic paths to antidepressant efficacy
}

\author{
Pierre-Eric Lutz \\ McGill Group for Suicide Studies, Douglas Mental Health University Institute, McGill University, Montreal, Québec, Canada
}

Submitted 20 December 2012; accepted in final form 23 January 2013

Lutz P.-E. Multiple serotonergic paths to antidepressant efficacy. $J$ Neurophysiol 109: 2245-2249, 2013. First published January 23, 2013; doi:10.1152/jn.01093.2012.-Depression is a leading cause of disability worldwide. Brain mechanisms underlying the clinical antidepressant efficacy of selective serotonin reuptake inhibitors (SSRI), currently the first-line treatment, remain poorly understood. Recent animal studies have implicated multiple serotonin receptor subtypes in SSRI response, opening new therapeutic perspectives.

serotonin receptor; selective serotonin reuptake inhibitor; depression; neurogenesis

DEPRESSION, DEFINED MAINLY by depressed mood and anhedonia, is a leading cause of disability worldwide. The serendipitous discovery 60 years ago of the antidepressant properties of tricyclics, and later of selective serotonin reuptake inhibitors (SSRI), has prompted scientists to investigate the role of the serotonergic system in antidepressant medication and depression pathophysiology. Here, we summarize recent findings from rodent models indicating that different subtypes of serotonin (5-HT) receptors regulate the activity of 5-HT neurons, and mediate the antidepressant-like efficacy of SSRI.

Serotonergic neurons are mainly located in the midbrain dorsal raphe nucleus (DRN) and send axonal projections throughout the whole brain, where released 5-HT targets 14 different receptor types (Hannon and Hoyer 2008). Serotonergic neurons can be identified by their typical pattern of electrophysiological activity (a slow and regular firing rate, with long-duration positive action potentials). These neurons express the molecular target of SSRI, the 5-HT transporter (SERT), in both their somato-dendritic compartment and axon terminals (Fig. 1A). At both levels, acute SSRI treatment inhibits SERT and increases 5-HT concentration in the extracellular space. In the DRN, increased release of 5-HT activates the inhibitory $\mathrm{G}_{\mathrm{i}}$-coupled $5-\mathrm{HT}_{1 \mathrm{~A}}$ receptor $\left(5-\mathrm{HT}_{1 \mathrm{~A}} \mathrm{R}\right)$, which is expressed by 5-HT neurons as an autoreceptor. 5- $\mathrm{HT}_{1 \mathrm{~A}} \mathrm{R}$ activation in turn decreases the firing rate of 5-HT neurons and their neurotransmitter release, thus opposing the effect of SSRI on axon terminals. Therefore, due to DRN 5- $\mathrm{HT}_{1 \mathrm{~A}} \mathrm{R}$ negative feedback, acute SSRI treatment only slightly increases the endogenous serotonergic tone in projection regions (Blier and de Montigny 1994).

SSRI typically require 4-6 wk to achieve antidepressant efficacy in the clinic, and neuroadaptations responsible for this delayed onset-of-action are extensively studied. One of the earliest proposed mechanisms was the desensitization of $5-\mathrm{HT}_{1 \mathrm{~A}} \mathrm{R}$ in the DRN (Blier and de Montigny 1994). Upon chronic SSRI treatment, 5-HT neurons return to a normal firing rate through $5-\mathrm{HT}_{1 \mathrm{~A}} \mathrm{R}$ desensitization, thereby potentiating the

\footnotetext{
Address for reprint requests and other correspondence: P.-E. Lutz, McGil Group for Suicide Studies, Douglas Mental Health Univ. Institute, McGill Univ., Montreal, QC, Canada H4H 1R3 (e-mail: pierreeric.lutz@gmail.com).
}

serotonergic tone in virtually all DRN projection regions (Fig. $1 B$ ). Accordingly, decreased $5-\mathrm{HT}_{1 \mathrm{~A}} \mathrm{R}$ function would be expected to result in decreased autoinhibition and faster SSRI response. However, combining SSRI and a specific 5- $\mathrm{HT}_{1 \mathrm{~A}} \mathrm{R}$ antagonist (such as WAY100635) has failed to produce fast antidepressant response in animal models.

Additional complexity comes from the fact that the $5-\mathrm{HT}_{1 \mathrm{~A}} \mathrm{R}$ is also expressed as a heteroreceptor by forebrain non-serotonergic neurons. During chronic SSRI treatment, the serotonergic tone acting at every postsynaptic 5-HT receptor, including 5- $\mathrm{HT}_{1 \mathrm{~A}}$ heteroreceptor, is potentiated. Activation of these heteroreceptors, notably in the hippocampus, has been implicated in SSRI antidepressant efficacy, and may be blocked during combined therapy with a $5 \mathrm{HT}_{1 \mathrm{~A}} \mathrm{R}$ antagonist (Lucas et al. 2007). Moreover, 5-HT ${ }_{1 \mathrm{~A}}$ heteroreceptors indirectly regulate the activity of 5-HT neurons. Activation of $5-\mathrm{HT}_{1 \mathrm{~A}} \mathrm{R}$ expressed by layer 5 pyramidal neurons in the prefrontal cortex (PFC) was shown to decrease the firing rate of 5-HT neurons, a negative long-feedback loop that mimics activation of DRN autoreceptors (Celada et al. 2001). How this cortical receptor pool adapts during chronic SSRI treatment, and its behavioral relevance for antidepressant efficacy, remains poorly understood.

To manipulate specifically $5-\mathrm{HT}_{1 \mathrm{~A}}$ autoreceptors and determine their role in SSRI behavioral effects, Richardson-Jones et al. (2010) recently used a conditional genetic approach. They compared adult mice showing normal levels (Auto1A-High) or a $30 \%$ genetic deletion (Auto1A-Low) of 5-HT $\mathrm{HA}_{1 \mathrm{~A}}$ autoreceptors, while expression of $5-\mathrm{HT}_{1 \mathrm{~A}}$ heteroreceptors was unchanged. Surprisingly, this modest decreased autoinhibition in Auto1A-Low mice had strong effects on 5-HT neurons and emotional responses, and was sufficient to increase the spontaneous firing activity of 5-HT neurons. Upon acute SSRI exposure, reduced autoinhibition led to increased 5-HT release in the two projection regions examined (PFC and hippocampus). Importantly, Auto1A-Low mice showed enhanced behavioral response to SSRI in the novelty suppressed feeding test, a measure of hyponeophagia classically responsive to chronic but not acute treatment. Eight or 26 days of treatment with the SSRI fluoxetine had antidepressant-like effects in Auto1ALow mice, whereas Auto1A-High mice showed no response for either treatment duration. These results therefore suggest that the level of $5-\mathrm{HT}_{1 \mathrm{~A}} \mathrm{R}$ expression in the DRN partly determines the onset of SSRI antidepressant-like effects.

The 5- $\mathrm{HT}_{1 \mathrm{~B}}$ receptor $\left(5-\mathrm{HT}_{1 \mathrm{~B}} \mathrm{R}\right)$ is another $\mathrm{G}_{\mathrm{i}}$-coupled receptor, expressed both as an auto- and heteroreceptor. In contrast to the somato-dendritic $5-\mathrm{HT}_{1 \mathrm{~A}} \mathrm{R}$ autoreceptor, the $5-\mathrm{HT}_{1 \mathrm{~B}} \mathrm{R}$ is localized in axon terminals of 5-HT neurons (Fig. $1 A)$, thereby controlling 5 -HT release in projection regions. Chronic SSRI treatment was shown to induce desensitization and reduced expression of $5-\mathrm{HT}_{1 \mathrm{~B}}$ autoreceptors, likely con- 
Fig. 1. Brain substrates and serotonin $(5-\mathrm{HT})$ receptors implicated in antidepressant-like properties of selective serotonin reuptake ininhibit the serotonin transporter (SERT; green arrows) in both the dorsal raphe nucleus (DRN), the cell-body region of 5-HT neurons, and in their axon terminals. Thus, acute SSRI exposure potentially increases the endogenous 5-HT tone at every receptor type. In particular, activations of 5- $\mathrm{HT}_{1 \mathrm{~A}}$ and $5-\mathrm{HT}_{2 \mathrm{~B}}$ autoreceptors in the DRN, respectively, decrease and increase the firing rate of 5-HT neurons, and correspond to local negative and positive feedback mechanisms (blue and purple circular arrows). $5-\mathrm{HT}_{1 \mathrm{~B}} \mathrm{R}$ expressed by 5 -HT neurons in their axon terminals also contribute to autoinhibition. Furthermore, 5- $\mathrm{HT}_{1 \mathrm{~A}}$ and $5-\mathrm{HT}_{4}$ heteroreceptors expressed by prefrontal cortex (PFC) layer 5 pyramidal neurons, respectively, inhibit and activate 5-HT neurons, in negative and positive long-feedback loops (blue and orange long arrows). $B$ : upon acute and chronic SSRI treatment (2-3 wk), a complex cascade of brain adaptations occurs at different brain sites and contributes to antidepressant-like efficacy. Notably, desensitization of $5-\mathrm{HT}_{1 \mathrm{~A}}$ and $5-\mathrm{HT}_{1 \mathrm{~B}}$ autoreceptors is thought to increase the endogenous serotonergic tone, in turn acting on: 1) cortical 5- $\mathrm{HT}_{4} \mathrm{R}$, 2) hippocampal (Hipp) neurogenesis, and 3) $\mathrm{CA} 35-\mathrm{HT}_{1 \mathrm{~A}}$ heteroreceptors. Subacute (3 days) activation of $5-\mathrm{HT}_{4}$ receptors mimics several effects of SSRI and achieves fast antidepressant responses. Whether CA3 $5-\mathrm{HT}_{1 \mathrm{~A}} \mathrm{R}$ contributes to increased neurogenesis during chronic SSRI treatment, and whether cortical-striatal $5-\mathrm{HT}_{4} \mathrm{R}$ in $\mathrm{S} 100 \alpha$ positive cells (see text for details) mediates the fast-acting properties of 5-HT4R agonists, remain to be addressed (dashed arrows). hibitors (SSRI) in rodent models. A: SSRI

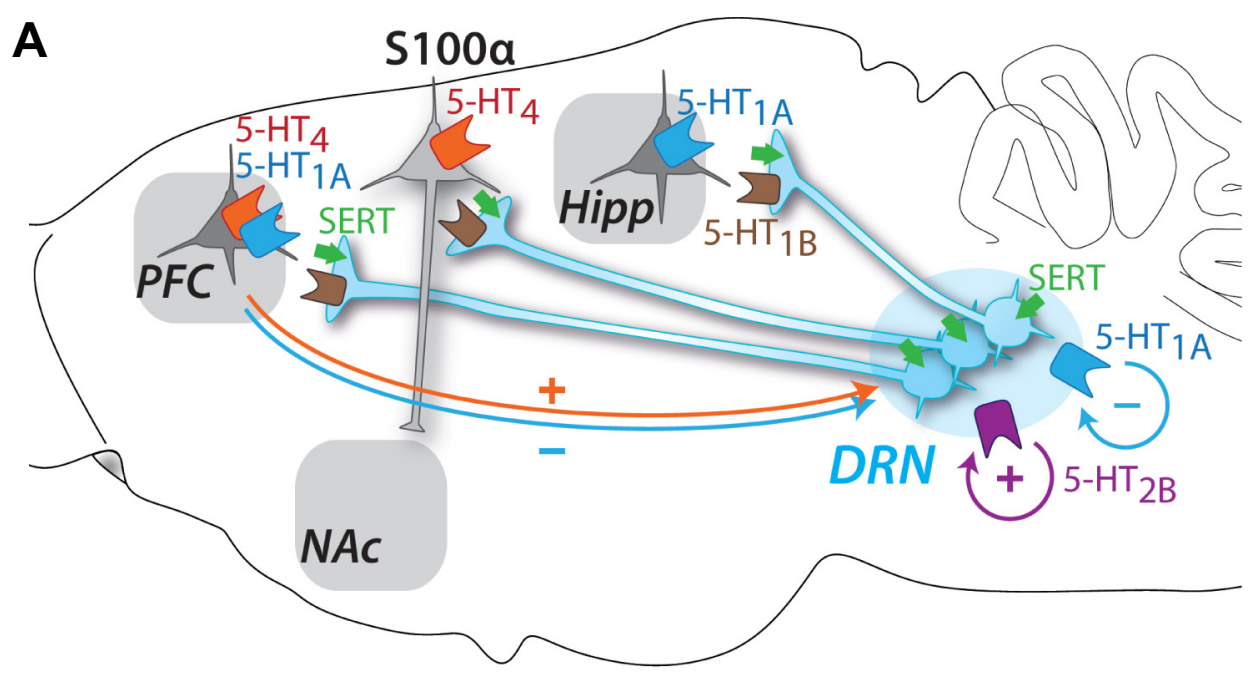

B

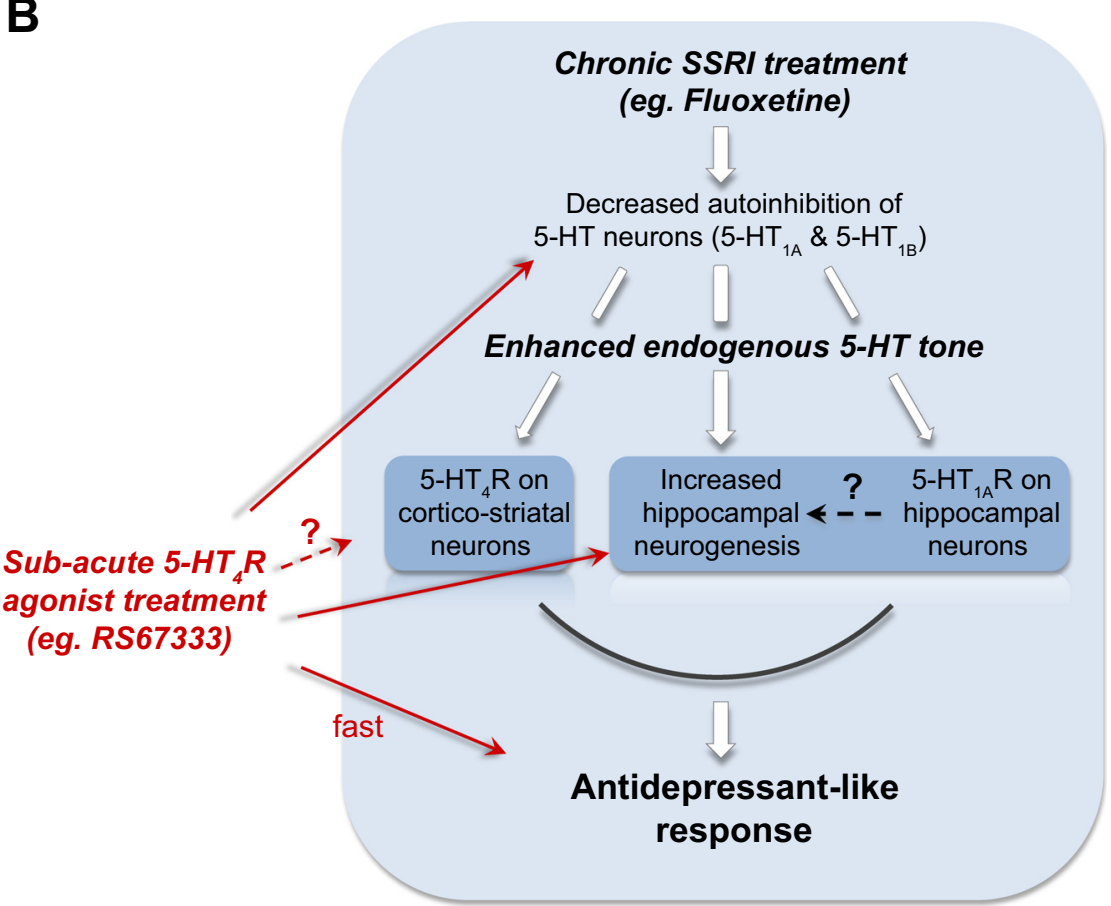

tributing to increased serotonergic tone during SSRI exposure. These effects, however, appear less robust than for the $5-\mathrm{HT}_{1 \mathrm{~A}} \mathrm{R}$, and their relevance in the behavioral onset of action or efficacy of SSRI remains poorly characterized in animal models (see McDevitt and Neumaier 2011 for a review). More recently, it was shown that activity of the $5-\mathrm{HT}_{1 \mathrm{~B}} \mathrm{R}$ is regulated by the $\mathrm{S} 100 \alpha$, a protein that anchors the $5-\mathrm{HT}_{1 \mathrm{~B}} \mathrm{R}$ and other 5-HT receptors at the cell membrane, notably during chronic SSRI exposure (see below and Svenningsson et al. 2006).

Another neuroadaptation triggered by chronic, but not acute, SSRI treatment is the generation of new neurons in the dentate gyrus of the hippocampus. Ablation of hippocampal neurogenesis by X-ray irradiation was shown to abolish SSRI antidepressant-like efficacy in the novelty suppressed feeding test (Santarelli et al. 2003). Interestingly, neurogenic and antidepressant-like effects of the SSRI fluoxetine were lost in $5-\mathrm{HT}_{1 \mathrm{~A}} \mathrm{R}$ constitutive knockout (KO) mice, indicating that they occur downstream of this receptor's signaling (Fig. 1B). Avail- able data suggest that both $5-\mathrm{HT}_{1 \mathrm{~A}}$ auto- and heteroreceptors may mediate SSRI neurogenic effects. Decreased 5-HT $1 \mathrm{~A}$ autoinhibition may favor increased SSRI-induced serotonergic activation, promoting faster neurogenesis and enhanced antidepressant response. Genetic polymorphisms affecting the expression (Lemonde et al. 2003), coupling efficiency, or transcriptional regulation of the $5-\mathrm{HT}_{1 \mathrm{~A}} \mathrm{R}$, have been suggested and will require further investigation (see Albert 2012; McDevitt and Neumaier 2011 for detailed reviews). Alternatively, hippocampal 5- $\mathrm{HT}_{1 \mathrm{~A}}$ heteroreceptors may directly control neurogenesis. Genetic deletion of $5-\mathrm{HT}_{1 \mathrm{~A}}$ heteroreceptors has been recently achieved in glutamatergic neurons of the forebrain (Richardson-Jones et al. 2011), and future studies should explore SSRI response in these mice, in which $5-\mathrm{HT}_{1 \mathrm{~A}} \mathrm{R}$ are undetectable in the whole hippocampus.

To bypass $5-\mathrm{HT}_{1 \mathrm{~A}} \mathrm{R}$ and $5-\mathrm{HT}_{1 \mathrm{~B}} \mathrm{R}$ autoinhibitions, researchers have looked for direct activators of 5-HT neurons, which may be endowed with fast neurogenic and antidepressant 
properties. Within this line, activation of the excitatory $\mathrm{G}_{\mathrm{q}}$ coupled $5-\mathrm{HT}_{2 \mathrm{~B}}$ receptor $\left(5-\mathrm{HT}_{2 \mathrm{~B}} \mathrm{R}\right)$ in the $\mathrm{DRN}$ was shown to increase local 5-HT release (Doly et al. 2008). Considering that the $5-\mathrm{HT}_{2 \mathrm{~B}} \mathrm{R}$ is expressed by DRN 5-HT neurons (Diaz et al. 2012), this autoreceptor appears to be responsible for a local positive feedback that opposes $5-\mathrm{HT}_{1 \mathrm{~A}} \mathrm{R}$ and $5-\mathrm{HT}_{1 \mathrm{~B}} \mathrm{R}$ activities (Fig. 1A). In addition, the $5-\mathrm{HT}_{2 \mathrm{~B}} \mathrm{R}$ is a crucial mediator of SSRI pharmacological and behavioral effects. Microdialysis experiments indicated that enhanced 5-HT release induced in the hippocampus by acute SSRI exposure was strongly reduced by either systemic pharmacological blockade or genetic ablation of the $5-\mathrm{HT}_{2 \mathrm{~B}} \mathrm{R}$ (Diaz et al. 2012). Furthermore, neurogenic and antidepressant-like effects of chronic SSRI treatment were also abolished by pharmacological blockade or genetic ablation of $5-\mathrm{HT}_{2 \mathrm{~B}} \mathrm{R}$ (Diaz et al. 2012). Thus, 5-HT $\mathrm{HA}_{\mathrm{A}}$ and $5-\mathrm{HT}_{2 \mathrm{~B}}$ autoreceptors oppositely modulate the activity of 5-HT neurons, and both receptors are controlling behavioral response to chronic SSRI treatment.

In view of these data, activation of the $5-\mathrm{HT}_{2 \mathrm{~B}} \mathrm{R}$ may now emerge as a therapeutic target in depression, despite concerns about potential cardiac toxicity (Hutcheson et al. 2011). In the forced swim test, a classical rodent screen for antidepressants, acute systemic administration of the $5-\mathrm{HT}_{2 \mathrm{~B}} \mathrm{R}$ agonist BW723C86 decreased despair-like behavior with similar efficacy compared with acute treatment with the SSRI fluoxetine. In the novelty suppressed feeding test, BW723C86 also had an antidepressant-like effect, similar to chronic fluoxetine. Somewhat surprisingly, a 4-wk treatment with BW723C86 was required in the later paradigm, suggesting that activation of serotonergic neurons through the $5-\mathrm{HT}_{2 \mathrm{~B}} \mathrm{R}$ does not achieve fast antidepressant-like effect, and may be hampered by homeostatic processes. Additional studies are required to assess, during the course of acute and prolonged $5-\mathrm{HT}_{2 \mathrm{~B}} \mathrm{R}$ signaling, both $5-\mathrm{HT}_{2 \mathrm{~B}} \mathrm{R}$ sensitivity and adaptations at other 5-HT receptors, which together determine the electrophysiological activity pattern of 5-HT neurons. Alternately, considering that $5-\mathrm{HT}_{2 \mathrm{~B}} \mathrm{R}$ expression is low in the DRN and restricted to a few regions of the brain (Hannon and Hoyer 2008), one could speculate that systemic activation of this receptor may act on a subset of 5-HT neurons, possibly targeting specific projection areas with an overall limited impact on mood circuits.

The $5-\mathrm{HT}_{4} \mathrm{R}$ is another excitatory 5-HT receptor type that is coupled to $\mathrm{G}_{\mathrm{s}}$ proteins. This receptor is poorly expressed in the DRN, but is enriched in the striatum, the hippocampus, and cortical areas. In rat, continuous systemic administration of a $5-\mathrm{HT}_{4} \mathrm{R}$ agonist (prucalopride or RS67333) rapidly increased the firing of 5-HT neurons, reaching a maximum after 3 days (Lucas et al. 2005). This potentiation persisted after a 3-wk treatment, suggesting that the $5-\mathrm{HT}_{4} \mathrm{R}$ does not desensitize. To localize where the $5-\mathrm{HT}_{4} \mathrm{R}$ operates to control 5-HT neurons, overexpression experiments were performed using viral vectors. In the PFC, but not in the striatum or the hippocampus, $5-\mathrm{HT}_{4} \mathrm{R}$ overexpression enhanced the firing rate of around 50\% of DRN 5-HT neurons, revealing a positive long-feedback loop originating in the cortex (Fig. 1A). The next step was to evaluate the antidepressant potential of $5-\mathrm{HT}_{4} \mathrm{R}$ agonists compared with SSRI (Lucas et al. 2007). In the forced swim test, acute systemic administration of $5-\mathrm{HT}_{4} \mathrm{R}$ agonists decreased despair-like behavior, similar to the SSRI citalopram. In olfactory bulbectomy and chronic mild stress, two models of de- pression, prolonged depressive-like behaviors were also reversed by the $5-\mathrm{HT}_{4} \mathrm{R}$ agonist RS67333. The latter antidepressant-like effect appeared in 3 days only, much faster than with citalopram ( $2 \mathrm{wk}$ ). Therefore, $5-\mathrm{HT}_{4} \mathrm{R}$ agonists represent the first putative fast-acting serotonergic antidepressants.

The authors then wondered whether neuronal mechanisms classically implicated in SSRI actions would be recruited faster upon $5-\mathrm{HT}_{4} \mathrm{R}$ activation (Fig. $1 B$ ): desensitization of DRN $5-\mathrm{HT}_{1 \mathrm{~A}}$ autoreceptors, activation of hippocampal 5-HT $\mathrm{HA}_{1 \mathrm{~A}}$ heteroreceptors, and neurogenesis (Lucas et al. 2007). As already mentioned, acute SSRI exposure decreases the firing of 5-HT neurons in a $5-\mathrm{HT}_{1 \mathrm{~A}} \mathrm{R}-$, dose-dependent manner. After systemic activation of the $5-\mathrm{HT}_{4} \mathrm{R}$ over 3 days, higher doses of the SSRI citalopram were required to inhibit 5-HT neurons, indicating that $5-\mathrm{HT}_{1 \mathrm{~A}} \mathrm{R}$ desensitized more rapidly than previously described for SSRI (2-3 wk). In the hippocampus, CA3 pyramidal neurons are classically under tonic inhibition, notably through 5-HT ${ }_{1 \mathrm{~A}}$ heteroreceptors. As expected, systemic activation of the $5-\mathrm{HT}_{4} \mathrm{R}$ potentiated the inhibition of CA3 neurons, an effect that was blocked by local infusion of a $5-\mathrm{HT}_{1 \mathrm{~A}} \mathrm{R}$ antagonist in the hippocampus. Finally, a 3-day treatment with RS67333 was sufficient to increase both cellular proliferation and survival in the hippocampus, which were known to require at least 11 days of SSRI treatment (Santarelli et al. 2003). Thus, subacute $5-\mathrm{HT}_{4} \mathrm{R}$ signaling recapitulates various effects of chronic SSRI treatment. 5- $\mathrm{HT}_{4} \mathrm{R}$ agonists primarily activate a PFC-DRN circuitry, in turn enhancing the serotonergic transmission to the hippocampus and correlating with fast antidepressant-like response.

It remains to be determined whether the observed increased hippocampal 5- $\mathrm{HT}_{1 \mathrm{~A}} \mathrm{R}$ signaling and neurogenesis are responsible for the remarkably fast antidepressant-like properties of the $5-\mathrm{HT}_{4} \mathrm{R}$ agonist RS67333. It would be interesting to assess RS67333 behavioral effects in the absence of hippocampal neurogenesis, such as previously performed for SSRI (using X-ray irradiation, see Santarelli et al. 2003). In addition, activation of $5-\mathrm{HT}_{4} \mathrm{R}$ impacts roughly half of DRN 5-HT neurons, and beyond the hippocampus, is likely to modify 5-HT release in other brain regions relevant for mood regulation. Ultimately, activation of $5-\mathrm{HT}_{4} \mathrm{R}$ may have fast-acting properties independently of any change in 5-HT neurons firing, and may act directly at striatal or cortical structures to promote antidepressant-like effects.

Schmidt et al. recently reported important evidence in support of this provocative hypothesis (Schmidt et al. 2012). The authors used translating ribosome affinity purification (TRAP), a technological breakthrough based on the transgenic tagging of a ribosomal protein in specific cell types. Tagged ribosomes can be immunopurified so as to isolate associated, translating mRNAs. Here, this method was applied to $\mathrm{S} 100 \alpha$-expressing neurons. This population was chosen because previous reports indicated that $\mathrm{S} 100 \alpha$ (also called p11) acts as an anchoring protein that binds to several $5-\mathrm{HT}$ receptors, including $5-\mathrm{HT}_{4} \mathrm{R}$, and stabilizes their localization at the cell surface (WarnerSchmidt et al. 2009). In a first step, retrograde tracing experiments indicated that cell bodies of S100 $\alpha$-tagged neurons are located in layer 5 of frontal, motor, and sensory cortices, and send axonal projections to the dorsal striatum and controlateral cortex. Microarray technology and TRAP were then combined to characterize cortico-striatal neurons. These neurons showed a specific transcriptomic signature that was highly 
distinct from that of cortico-pontine neurons, another pyramidal cell type located in the cortical layer 5. Cortico-striatal neurons also showed a strong sensitivity to chronic SSRI treatment, because 2 wk of fluoxetine treatment regulated 62 genes in this cell type (but only 4 genes in cortico-pontine neurons). Most importantly, chronic SSRI treatment induced a striking 16-fold upregulation of the 5- $\mathrm{HT}_{4} \mathrm{R}$ in $\mathrm{S} 100 \alpha$-positive neurons, while the expression of other serotonin receptors was left unaffected.

Furthermore, the authors investigated the role of corticostriatal neurons in SSRI behavioral response. A genetic conditional strategy was used to delete $\mathrm{S} 100 \alpha$ in the cortex. In these mice, antidepressant-like response to chronic fluoxetine was abolished in the tail suspension test (another measure of despair-like behavior, close to the forced swim) and the novelty suppressed feeding test, while the upregulation of the $5-\mathrm{HT}_{4} \mathrm{R}$ was significantly blunted. Therefore, these results show that the expression of the anchoring protein $\mathrm{S} 100 \alpha$ in cortico-striatal neurons is necessary for chronic SSRI antidepressant-like effects. They also strongly suggest a new mechanism for the delayed onset-of-action of SSRI, whereby an enhanced serotonergic tone acts on an upregulated pool of $5-\mathrm{HT}_{4} \mathrm{R}$ in S100 $\alpha$-expressing neurons. It is therefore possible that fastacting properties of the $5-\mathrm{HT}_{4} \mathrm{R}$ agonist RS67333 rely on the direct pharmacological activation of this cortico-striatal signaling, mimicking chronic effects of SSRI. Interestingly, the same group previously demonstrated that the effects of RS67333 in the forced swim and tail suspension tests are lost in S100 $\alpha$ constitutive KO mice (Warner-Schmidt et al. 2009). Future studies should explore models of depression and chronic SSRI efficacy (novelty suppressed feeding and chronic mild stress, for example) and test whether fast effects of RS67333 are retained after conditional deletion of $\mathrm{S} 100 \alpha$ in the cortex. Together, these findings reveal another brain region, in addition to the hippocampus, where SSRI act to achieve antidepressant-like response. The molecular mechanisms mediating upregulation of a single 5-HT receptor type, in a single cell population, during chronic SSRI exposure remain unknown. In the future, elucidating these mechanisms may open new therapeutic avenues.

Adding to the list of adaptations occurring at single 5-HT receptors described in this review, new molecular mechanisms regulating monoamine receptors have recently emerged, such as lipid rafts and adaptor proteins (see Bjork and Svenningsson 2011 for a review). Adaptor, or anchoring, proteins are capable of recruiting simultaneously multiple receptor types, and the aforementioned $\mathrm{S} 100 \alpha$ protein represents a promising target. Chronic SSRI treatment increases the cortical expression of S100 $\alpha$ (Schmidt et al. 2012), thus favoring the localization at the cell membrane of the 5- $\mathrm{HT}_{4} \mathrm{R}$, as well as of other 5-HT receptors: 5- $\mathrm{HT}_{1 \mathrm{~B}}$ and 5- $\mathrm{HT}_{1 \mathrm{D}}$ (Warner-Schmidt et al. 2009). The difficult task of assessing the role of anchoring proteins, and the specific combinations of 5-HT receptors they recruit, during SSRI treatment and antidepressant-like response is only beginning (Egeland et al. 2010).

In summary, the results from animal models reviewed here implicate several subtypes of 5-HT receptors in SSRI antidepressant-like efficacy. These anatomically dispersed 5-HT receptors together control the firing pattern of 5-HT neurons, in an intricate modulatory network. Cortical layer 5 pyramidal neurons express $5-\mathrm{HT}_{1 \mathrm{~A}}$ heteroreceptors and inhibit 5-HT neurons through a negative long-feedback loop. Two populations of cortical layer 5 neurons expressing $5-\mathrm{HT}_{4}$ heteroreceptors either activate 5-HT neurons through a positive longfeedback loop or project to the striatum (Fig. 1A), and both likely contribute to mood control. 5-HT neurons also selfregulate their firing activity through autoreceptors, with opposed negative $\left(5-\mathrm{HT}_{1 \mathrm{~A}} \mathrm{R}\right)$ and positive $\left(5-\mathrm{HT}_{2 \mathrm{~B}} \mathrm{R}\right)$ feedbacks in the DRN, as well as a negative feedback in axon terminals $\left(5-\mathrm{HT}_{1 \mathrm{~B}} \mathrm{R}\right)$. Finally, while they received less attention, other 5 -HT receptors are recruited by SSRI, such as $5-\mathrm{HT}_{6}$ (Svenningsson et al. 2007) and 5- $\mathrm{HT}_{7}$ (Mnie-Filali et al. 2011) receptors. SSRI ultimately potentiate the serotonergic transmission throughout the brain, and simultaneously act at autoand heteroreceptors. Notably, available evidence reveals that both hippocampal neurogenesis and cortico-striatal neurons are necessary for SSRI antidepressant-like effects. It remains unclear whether all these 5-HT receptors and neuronal substrates must act in concert to achieve antidepressant-like efficacy. A major goal for future studies will be to determine their relative contributions as a function of interindividual sources of variability, in animal models and in humans.

\section{ACKNOWLEDGMENTS}

I thank Brigitte Kieffer, Yvan Peterschmitt, and Michel Roux for critical reading of the manuscript.

\section{GRANTS}

I thank the Fondation pour la Recherche Médicale and the Fondation Fyssen for financial support.

\section{DISCLOSURES}

No conflicts of interest, financial or otherwise, are declared by the author(s).

\section{AUTHOR CONTRIBUTIONS}

P.-E.L. conception and design of research; P.-E.L. analyzed data; P.-E.L. interpreted results of experiments; P.-E.L. prepared figures; P.-E.L. drafted manuscript; P.-E.L. edited and revised manuscript; P.-E.L. approved final version of manuscript.

\section{REFERENCES}

Albert PR. Transcriptional regulation of the 5-HT1A receptor: implications for mental illness. Philos Trans R Soc Lond B Biol Sci 367: 2402-2415, 2012.

Bjork K, Svenningsson P. Modulation of monoamine receptors by adaptor proteins and lipid rafts: role in some effects of centrally acting drugs and therapeutic agents. Annu Rev Pharmacol Toxicol 51: 211-242, 2011.

Blier P, de Montigny C. Current advances and trends in the treatment of depression. Trends Pharmacol Sci 15: 220-226, 1994.

Celada P, Puig MV, Casanovas JM, Guillazo G, Artigas F. Control of dorsal raphe serotonergic neurons by the medial prefrontal cortex: involvement of serotonin-1A, GABA(A), and glutamate receptors. J Neurosci 21: 9917-9929, 2001.

Diaz SL, Doly S, Narboux-Neme N, Fernandez S, Mazot P, Banas SM, Boutourlinsky K, Moutkine I, Belmer A, Roumier A, Maroteaux L. 5-HT(2B) receptors are required for serotonin-selective antidepressant actions. Mol Psych 17: 154-163, 2012.

Doly S, Valjent E, Setola V, Callebert J, Herve D, Launay JM, Maroteaux L. Serotonin 5-HT2B receptors are required for 3,4-methylenedioxymethamphetamine-induced hyperlocomotion and 5-HT release in vivo and in vitro. J Neurosci 28: 2933-2940, 2008.

Egeland M, Warner-Schmidt J, Greengard P, Svenningsson P. Neurogenic effects of fluoxetine are attenuated in p11 (S100A10) knockout mice. Biol Psychol 67: 1048-1056, 2010. 
Hannon J, Hoyer D. Molecular biology of 5-HT receptors. Behav Brain Res 195: 198-213, 2008.

Hutcheson JD, Setola V, Roth BL, Merryman WD. Serotonin receptors and heart valve disease-it was meant 2B. Pharmacol Ther 132: 146-157, 2011.

Lemonde S, Turecki G, Bakish D, Du L, Hrdina PD, Bown CD, Sequeira A, Kushwaha N, Morris SJ, Basak A, Ou XM, Albert PR. Impaired repression at a 5-hydroxytryptamine $1 \mathrm{~A}$ receptor gene polymorphism associated with major depression and suicide. J Neurosci 23: 8788-8799, 2003.

Lucas G, Compan V, Charnay Y, Neve RL, Nestler EJ, Bockaert J, Barrot M, Debonnel G. Frontocortical 5-HT4 receptors exert positive feedback on serotonergic activity: viral transfections, subacute and chronic treatments with 5-HT4 agonists. Biol Psychol 57: 918-925, 2005.

Lucas G, Rymar VV, Du J, Mnie-Filali O, Bisgaard C, Manta S, LambasSenas L, Wiborg O, Haddjeri N, Pineyro G, Sadikot AF, Debonnel G. Serotonin(4) (5-HT(4)) receptor agonists are putative antidepressants with a rapid onset of action. Neuron 55: 712-725, 2007.

McDevitt RA, Neumaier JF. Regulation of dorsal raphe nucleus function by serotonin autoreceptors: a behavioral perspective. J Chem Neuroanat 41: 234-246, 2011.

Mnie-Filali O, Faure C, Lambas-Senas L, Mansari ME, Belblidia $\mathbf{H}$ Gondard E, Etievant A, Scarna H, Didier A, Berod A, Blier P, Haddjeri N. Pharmacological blockade of 5-HT(7) receptors as a putative fast acting antidepressant strategy. Neuropsychopharmacology 36: 1275-1288, 2011.

Richardson-Jones JW, Craige CP, Guiard BP, Stephen A, Metzger KL, Kung HF, Gardier AM, Dranovsky A, David DJ, Beck SG, Hen R,
Leonardo ED. 5-HT1A autoreceptor levels determine vulnerability to stress and response to antidepressants. Neuron 65: 40-52, 2010.

Richardson-Jones JW, Craige CP, Nguyen TH, Kung HF, Gardier AM, Dranovsky A, David DJ, Guiard BP, Beck SG, Hen R, Leonardo ED. Serotonin-1A autoreceptors are necessary and sufficient for the normal formation of circuits underlying innate anxiety. J Neurosci 31: 6008-6018, 2011.

Santarelli L, Saxe M, Gross C, Surget A, Battaglia F, Dulawa S, Weisstaub N, Lee J, Duman R, Arancio O, Belzung C, Hen R. Requirement of hippocampal neurogenesis for the behavioral effects of antidepressants. Science 301: 805-809, 2003.

Schmidt EF, Warner-Schmidt JL, Otopalik BG, Pickett SB, Greengard P, Heintz N. Identification of the cortical neurons that mediate antidepressant responses. Cell 149: 1152-1163, 2012.

Svenningsson P, Chergui K, Rachleff I, Flajolet M, Zhang X, El Yacoubi M, Vaugeois JM, Nomikos GG, Greengard P. Alterations in 5-HT1B receptor function by $\mathrm{p} 11$ in depression-like states. Science 311: 77-80, 2006.

Svenningsson P, Tzavara ET, Qi H, Carruthers R, Witkin JM, Nomikos GG, Greengard P. Biochemical and behavioral evidence for antidepressant-like effects of 5-HT6 receptor stimulation. J Neurosci 27: 4201-4209, 2007.

Warner-Schmidt JL, Flajolet M, Maller A, Chen EY, Qi H, Svenningsson $\mathbf{P}$, Greengard P. Role of p11 in cellular and behavioral effects of 5-HT4 receptor stimulation. J Neurosci 29: 1937-1946, 2009.

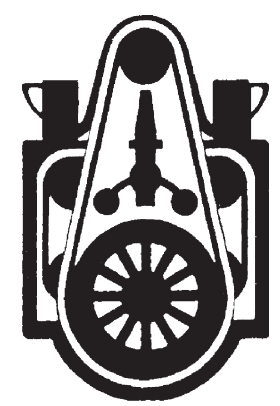

